\title{
A technique modification in the cannulation to the innominate artery in the surgical treatment of aortic dissection
}

\author{
Yang Yu, Tianxiang Gu*, Enyi Shi, Lei Yu and Chun Wang
}

\begin{abstract}
Background: A modified cannulation strategy to innominate artery was introduced which differs from traditional cannulation method used in aortic surgeries.

Case presentation: Four patients suffering from aortic dissections with or without other cardiac diseasees underwent surgical treatment by using the modified canulation technique. All patients had an uneventful perioperative period and discharged from the hospital without any complications.

Conclusions: Innominate artery cannulation using the modified cannula with "a hole in the back" is an easy and effective strategy for arch surgery.
\end{abstract}

Keywords: Aortic dissection, CPB components

\section{Background}

Innominate artery cannulation has been widely accepted in arch surgery since it was reported by Banbury and Cosgrove [1, 2]. In our department the technique has been used in the surgical treatment of Stanford A aortic dissections. The tip of the cannula was rotated during the switch between system perfusion and selective antegrade cerebral perfusion (SCP) (Fig. 1a) [3]. To simplify such procedure, a modification to the cannula was made and the clinical experience is presented.

\section{Case presentation}

There were four patients in the series. Two patients of type $\mathrm{B}$ dissection combined with coronary artery disease received stented elephant trunk implantation and CABG; one patient of type $B$ dissection combined with aortic valve insufficiency received stented elephant trunk implantation by an open aortic manner and tissue valve replacement; one patient of type A dissection received ascending aorta and hemiarch replacement combined with stented elephant trunk implantation.

\footnotetext{
* Correspondence: cmugtx@sina.com

Department of Cardiac Surgery, First Affiliated Hospital, China Medical University, Shenyang 110001, China
}

(C) 2015 Yu et al. Open Access This article is distributed under the terms of the Creative Commons Attribution 4.0 International License (http://creativecommons.org/licenses/by/4.0/), which permits unrestricted use, distribution, and reproduction in any medium, provided you give appropriate credit to the original author(s) and the source, provide a link to the Creative Commons license, and indicate if changes were made. The Creative Commons Public Domain Dedication waiver (http:// creativecommons.org/publicdomain/zero/1.0/) applies to the data made available in this article, unless otherwise stated.
A median sternotomy was performed, the innominate artery was mobilized to the bifurcation as well as left common carotid artery and left subclavian artery. After heparinzation, double purse-string sutures were made at the innominate artery. Then the innominate artery was stabbed and a home-made $22 \mathrm{~F}$ or $24 \mathrm{~F}$ wire-reinforced flexible short-tipped cannula with "a hole in the back" (Fig. 1b) was introduced. The hole was made at the bend opposite to the tip with a similar area as the normal opening of the cannula. Venous return was established with a 2-stage cannula introduced via the right atrium. When the core temperature was cooled to about $32{ }^{\circ} \mathrm{C}$, the ascending aorta was clamped, cardioplegia was perfused antegradely. The proximal procedures: distal anastomosis for CABG, aortic valve replacement or ascending aorta replacement, were performed. During the proximal procedure the core temperature was decreased sequentially to $26 \sim 28{ }^{\circ} \mathrm{C}$, then the circulation arrest was induced and a clamp was applied proximal to the innominate artery cannula (Fig. 1c). The antegrade SCP was induced with a rate of 5 to $10 \mathrm{ml} / \mathrm{kg} / \mathrm{min}$ with maintaining the right radial artery pressure at $40 \sim 50 \mathrm{mmHg}$. Such a pressure was almost the same as what was maintained during system perfusion. Then the arch was transected and the returning blood from left common carotid artery was well observed. A self-expandable stent 


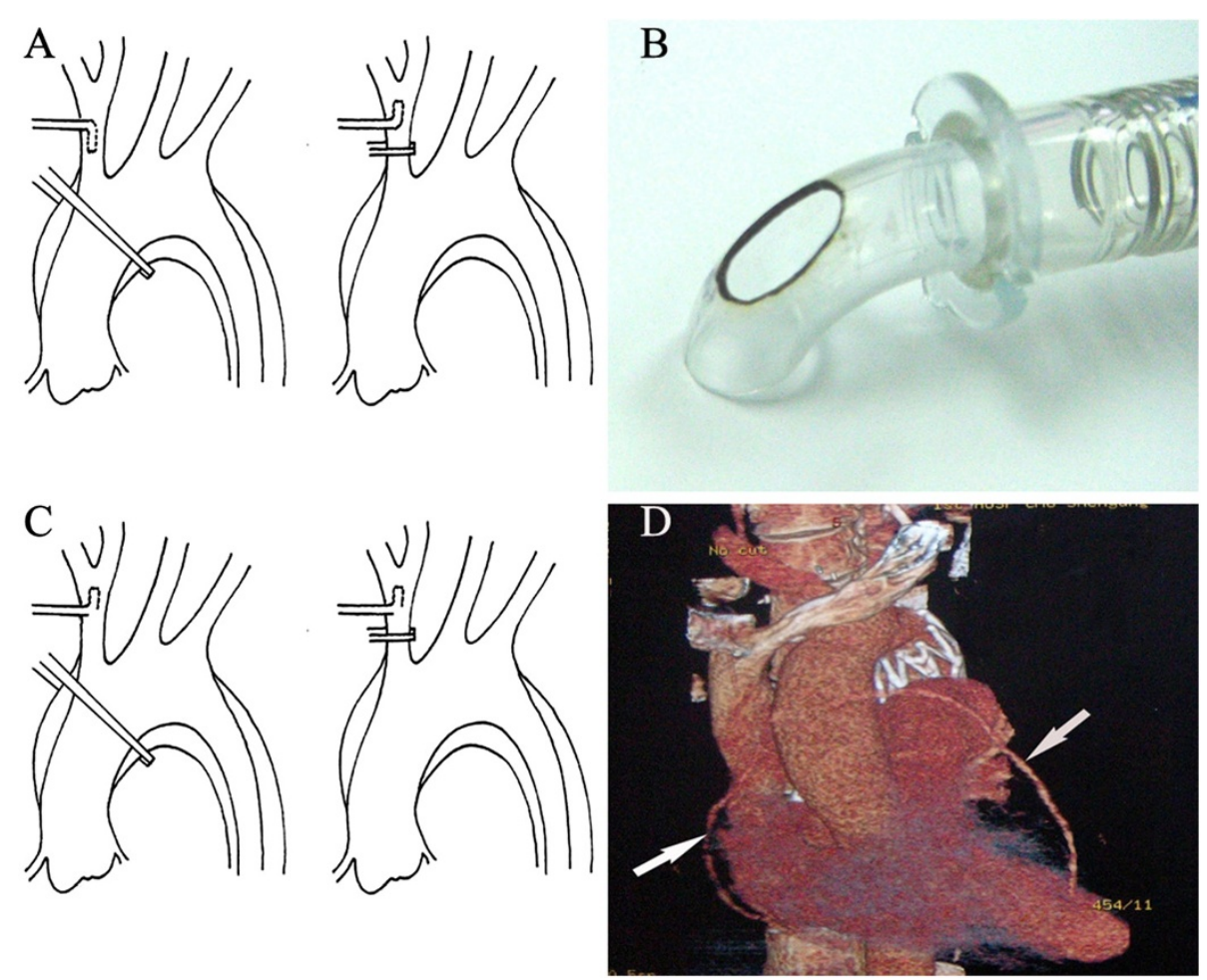

Fig. 1 a: Diagram of innominate artery cannulation using normal cannula. a, For cooling and rewarming, the tip of the cannula is pointing toward the arch and the crossclamp is placed at the ascending aorta. $\mathbf{b}$. For selective antegrade cerebral perfusion, the tip of the cannula is oriented toward the head and the crossclamp is placed proximal to the site of cannulation of the innominate artery. $\mathbf{b}$ : Photograph of modified innominate artery cannula with "a hole in the back". c: Diagram of innominate artery cannulation using modified cannula. a, For cooling and rewarming, the crossclamp is placed at the ascending aorta. $\mathbf{b}$, For selective antegrade cerebral perfusion, the crossclamp is placed proximal to the site of cannulation of the innominate artery. $\mathbf{d}$ : Postoperative computerized tomography angiography of a patient with type B dissection and coronary artery disease. Arrows show the venous graft for coronary artery bypass graft. The mental stent of stented elephant graft is located inside the descending aorta

vessel prosthesis with a length of 8 to $10 \mathrm{~cm}$ was inserted into the descending aorta. The proximal end of the stent was positioned just distal to the opening of the left subclavian artery and proximal free edge was attached to the aorta with a continuous suture. The incision at the aortic arch was closed. Then the clamp on innominate artery was removed and the ascending aorta was occluded again. Systemic perfusion was restored gently. Then the rewarming progress was induced.

All patients had an uneventful perioperative period and discharged without any complication. Permanent neurologic dysfunction and paraplegia did not occur in the patients. Postoperative CTA of a patient with type B dissection and coronary artery disease is shown in Fig. 1d.

\section{Conclusions}

Innominate artery cannulation is well accepted in aortic arch surgery, for it can be used during total $\mathrm{CPB}$ as well as $\mathrm{SCP}$. Compared with traditional technique using right axillary artery cannulation to induce SCP, the innominate artery cannulation processes several advantages: First, a second incision to gain access to the axillary artery can be avoided. Second, the innominate artery is usually larger than the right subclavian or axillary arteries, total CPB flow can be easily achieved without high pump pressures, also the cannulation can be easier. Third, the SCP pressure can be monitored by a routine right radial arterial line. Finally, the risk for brachial plexus injury or right axillary artery injury can be avoided [4-6]. During the aortic procedure involving the arch, the circulation arrest and SCP are often induced by an added subclavian incision and the cannulation in the right axillary artery. Our centre had reported a series of surgical treatment for the patients with type A dissections using innominate cannulation and the result is encouraging. Based on this technique, a modification to the cannula was made: a hole with a similar size as the normal opening was made in the back of the tip. During systemic perfusion, blood can be perfused from the hole to the aorta. When the innominate artery was occluded, SCP can be induced through the normal opening of the cannula. Therefore, the rotation of the tip during switch between system perfusion and SCP was avoided $[7,8]$. The surgical procedure for arch was further simplified. No permanent neurologic dysfunction 
and paraplegia was detected in the series. The current results indicted that both system perfusion and SCP can be performed by using the modified cannula to innominate artery without complications and such technique is an easy and effective strategy for arch surgery.

However the cannulation technique itself has some limitations: 1 . The exposure of the innominate artery must long enough so that the clamp could be applied to the proximal site of the innominate artery without touching the cannula; 2. For the patients with the brachiocephalic vessels especially the innominate artery affected by dissections, this technique should be abandoned. 3 . If atherosclerosis, stenosis, or plaques was found in the innominate artery, the cannulation should be cautiously.

\section{Competing interests}

There are no sources of funding for the work or personal conflicts of interests of any of the authors.

\section{Authors' contributions}

Dr. Gu designed the clinical study and performed operations. Dr. Yu designed the cannula andwrote the paper. Dr. Shi, Dr. Yu and Dr. Wang took part in the clinical study. All authors read and approved the final manuscript.

Received: 13 March 2015 Accepted: 16 December 2015

Published online: 30 December 2015

\section{References}

1. Banbury MK, Cosgrove 3rd DM. Arterial cannulation of the innominate artery. Ann Thorac Surg. 2000;69:957.

2. Ji S, Yang J, Chen C. Brain protection by using innominate artery cannulation during aortic arch surgery. Chin J Thorac Cardiovasc Surg. 2006;22:424-5.

3. Shi E, Gu T, Yu L, Xiu Z, Zhang Z, Wang C, et al. Repair of Stanford type A aortic dissection with ascending aorta and hemiarch replacement combined with stent-graft elephant trunk technique by using innominate cannulation. J Thorac Cardiovasc Surg. 2011;142:1458-63.

4. Schachner T, Laufer G, Vertacnik K, Bonaros N, Nagiller J, Bonatti J. Is the axillary artery a suitable cannulation site in aortic surgery? J Cardiovasc Surg (Torino). 2004;45:15-9.

5. Sabik JF, Nemeh H, Lytle BW, Blackstone EH, Gillinov AM, Rajeswaran J, et al. Cannulation of the axillary artery with a side graft reduces morbidity. Ann Thorac Surg. 2004;77:1315-20.

6. Sinclair MC, Singer RL, Manley NJ, Montesano RM. Cannulation of the axillary artery for cardiopulmonary bypass: safeguards and pitfalls. Ann Thorac Surg. 2003:75:931-4.

7. Huang FJ, Wu Q, Ren CW, Lai YQ, Yang S, Rui QJ, et al. Cannulation of the innominate artery with a side graft in arch surgery. Ann Thorac Surg. 2010; 89:800-3.

8. Ji S, Yang J, Ye X, Wang X. Brain protection by using innominate artery cannulation during aortic arch surgery. Ann Thorac Surg. 2008;86(3):1030-2.

Submit your next manuscript to BioMed Central and we will help you at every step:

- We accept pre-submission inquiries

- Our selector tool helps you to find the most relevant journal

- We provide round the clock customer support

- Convenient online submission

- Thorough peer review

- Inclusion in PubMed and all major indexing services

- Maximum visibility for your research

Submit your manuscript at www.biomedcentral.com/submit 